\title{
A PROPRIEDADE DO HOSPITAL DE STA. MARIA DA VITÓRIA (BATALHA) NOSÉC. XV
}

Os estudos sobre a propriedade fundiária em Portugal ao longo da Idade Média são praticamente unânimes em considerarem a propriedade alodial, na posse plena das camadas populares, como "uma pequena fracção" de todo o seu conspecto global No entanto, e sem discordar desta leitura basilar de toda a história económica agrária medieval de Portugal, um número relativamente crescente de estudos ultimamente realizados indicia que, não obstante a sua dimensão global ocupar um peso reduzido no todo fundiário, a pequena propriedade alodial desempenhava um papel de primeira ordem no quotidiano material das populações quer exclusivamente rurais, quer urbanas $\left(^{2}\right)$.

(') A. H. Oliveira Marques, Portugal na Crise dos Séculos XIV e XV, vol. IV da Nova História de Portugal (dir. de Joel Serrão e A. H. de Oliveira Marques), Lisboa, ed. Presença, 1986, pp. 76-77; José Mattoso, Identificação de um País. Ensaio sobre as Origens de Portugal, 1096-1325, vol. I - Oposição, Lisboa, ed. Estampa, 1985, pp. 452-456.

$\left.{ }^{(}\right)$Entre outros, cite-se Iria Gonçalves e Fátima Botão, "As Confrarias Medievais da Região de Alcanena" in Boletim do Centro de Estudos Históricos e Etnológicos, IV, Ferreirado Zêzere, ed. C.M.F.Z., 1989, pp. 41-54; Maria Helena da Cruz Coelho, $O$ Baixo Mondego nos finais da Idade Média (Estudo de História Rural), Coimbra, Fac. de Letras, 1983,pp. 123-129; A. H. de Oliveira Marques, Introdução à História da Agricultura em Portugal A questão cerealífera durante a Idade Média, Lisboa, ed. Cosmos, 1968, pp. 63-80; Bernardo Vasconcelos e Sousa, A propriedade das albergarias de Évora nos 
Porventura, seria desejável que possuíssemos dados numéricos ou estatísticos abundantes sobre este tema, para podermos avançar com novas conclusões e linhas de leitura interpretativa. Mas, como é conhecido, a pobreza generalizada das fontes úteis à história agrária portuguesa, para este período, não permite o triunfo de análises solidamente baseadas quanto à dimensionalidade espacial da propriedade fundiária e, sobretudo, quanto ao peso efectivo das produções agrícolas, em função da tipologia da propriedade das glebas donde emanavam, que eram canalizadas para o abastecimento dos mercados consumidores $\left(^{3}\right)$.

Neste contexto, cremos ser útil continuar a analisar casos específicos ou monográficos, a fim de que se possa obter, num futuro próximo, um quadro quantitativamente mais preciso sobre a estrutura fundiária própria do País nos séculos medievais.

Torna-se útil, pois, publicar os resultados obtidos a propósito duma pequena instituição assistencial, sediada na actual vila da Batalha, e em tempos medievais na área de influência jurisdicional do concelho de Leiria, bem no centro do País estremenho. À antiga comarca da Estremadura, aliás, pertence o núcleo porventura mais significativo de estudos sobre o regime da propriedade que a historiografia portuguesa tem produzido nos últimos lustros $\left(^{4}\right)$. O que é justificável, antes de mais, por ser justamente neste espaço que mais informes documentais se têm encontrado propiciadores

finais da Idade Média, Lisboa, INIC, 1990, pp. 41 -101; Saul António Gomes, O Mosteiro de Santa Maria da Vitória no Século XV, Coimbra, ed. Inst. de Hist. da Arte da Fac. de Letras, 1990, pp. 191-216.

$\left({ }^{3}\right)$ Sobre esta questão, seja-nos lícito remeter para Robert Fossier (coord.) "Histoire des campagnes médiévales en France", in L'Histoire Médiévale en France, Bilan et Perspectives, Paris, ed. Seuil, 1991, pp. 13-30; Georges Duby, "La agricultura medieval, 900-1500", in Historia Economica de Europa (l).La Edad Media, (dir. Carlo Cipolla), Barcelona, ed. Ariel, 1981, pp. 189-193.

( ${ }^{4}$ ) Além das obras citadas nas notas 1 e 2, veja-se a síntese sobre esta questão em A. H. de Oliveira Marques, Guia do Estudante da História Medieval Portuguesa, Lisboa, ed. Estampa, 1988, 3. ${ }^{a}$ ed., pp. 77, 244-245; Armando Luís de Carvalho Homem, Amélia Andrade e Luís Amaral, "Por Onde Vem o Medievismo em Portugal", in Revista de História Económica e Social, n. ${ }^{\circ} 22$, Janeiro-Abril, 1988, Lisboa, pp. 115-138. 
de informação para o tipo de questões que nos ocupam. Zona litorânea, com uma rede complexa e densa de vias de comunicação, servida por bom número de portos marítimos, a Estremadura portuguesa viu surgir os maiores centros urbanos do País, naquele período, além dos maiores potentados eclesiásticos (v. g. Sta. Maria de Alcobaça, Sta. Cruz de Coimbra, Cabidos e Mitras de Lisboa e Coimbra), bem como um importantíssimo núcleo vital de toda a propriedade régia. A diversidade da propriedade nesta antiga Comarca era efectivamente uma realidade. A riqueza das suas gentes, e a abundância destas, levava a que as questões da propriedade e da sua distribuição assumissem uma dinâmica que importa conhecer.

É muito útil, assim, observar a constituição, bem como as estruturas materiais ou económicas, do património de uma instituição de beneficência do termo leiriense $\left(^{5}\right)$. O caso da confraria de N. Sra. da Vitória, na Batalha, iniciada em $1427\left(^{6}\right)$, pode ser paradigma. Primeiro porque é um caso, não isolado, de constituição de um património quase no final dos tempos medievos. Depois porque nos pode revelar o tipo de disponibilidade, quanto a terras e outras propriedades de âmbito rural, que se verifica numa região bastante procurada, e mesmo disputada, quer por institutos religio-

$\left({ }^{5}\right)$ No termo leiriense contam-se, pelo menos, 35 confrarias com origens medievas. A maior parte tem hospital ou albergue. No centro urbano, as instituições de assistência ascendem a um mínimo de 20 para pleno século XV. Dados levantados de $O$ Couseiro. Memórias do Bispado de Leiria, (reimpressão de $O$ Mensageiro, Leiria, 1980), e confirmados, na melhor parte, por documentação coeva.

(') A confraria de N. Sra. da Vitória, na Batalha, é caso particular, uma vez que é a única de que conhecemos documentação quatrocentista para toda a região de Leiria. Fundada em 1427, 0 ano da concordata com o clero em que D. João I foi mesmo" acusado (...) de desviar as esmolas dos hospitais, expulsar deles os pobres e fazê-los substituir por presos, que delapidavam todos os seus haveres" (Iria Gonçalves, "Formas Medievais de Assistência num Meio Estremenho", in Actas (...) A Pobreza e a Assistência aos Pobres na Península Ibérica durante a Idade Média, I, Lisboa, 1973, pp. 440), estipulava-se no seu compromisso um conjunto de preceitos de assistência na doença, na morte, de socorro mútuo e de acompanhamento espiritual, como era norma. Vd. Saul Gomes, $O$ Mosteiro de Santa Maria da Vitória..., pp. 363-367. 
sos, quer por leigos, como é o caso de alguma nobreza, da aristocracia vilã e até do próprio rei.

Esta razão parece pertinente, bastando citar o exemplo do Mosteiro da Batalha que teve dificuldades em adquirir e formar o seu património rural, numa época que coincide grosso modo com a da afirmação da confraria aqui analisada $\left(^{7}\right)$.

Com obrigações estatutárias que impunham gastos, com receitas e com despesas sazonalmente obrigatórias de realizar, a confraria tinha necessidade de um conjunto de bens rentáveis que lhe permitissem perenidade e consumação dos seus objectivos humanitários e religiosos.

O confronto doutros exemplos estremenhos rurais ( $\left.{ }^{8}\right)$ e urbanos $\left({ }^{9}\right)$ permitirá enquadrar num contexto económico as origens da instituição. Na base do seu património parece estar a doação feita por um qualquer "confrade" abastado, só depois a compra $\left({ }^{10}\right)$.

O Saul Gomes, op. cit., pp. 149-190.

$\left({ }^{8}\right)$ Iria Gonçalves, ob. cit., pp. 439-454; Eadem, "As Confrarias...", pp. 41-54.

(') Maria José Pimenta Ferro, "Nótulas para o Estudo da Assistência Hospitalar aos Pobres, em Lisboa: Os Hospitais de D. Maria de Aboim e do Conde D. Pedro", in Actas (...) Pobreza e a Assistência aos Pobres na Península Ibérica (...), cit., pp. 371-400. Eadem, "Para o Estudo das Confrarias Medievais Portuguesas: os compromissos de três Confrarias de Homens Bons Alentejanos", Estudos Medievais, n. ${ }^{\circ}$. Porto, 1987, pp. 55-72. Da bibliografia mais recente sobre instituições assistenciais cite-se: Maria Angela Godinho Beirante, Confrarias Medievais Portuguesas, Lisboa, ed. da autora, 1990; José Marques, A assistência no Norte de Portugal nos finais da Idade Média, Porto, sep. da Revista da Faculdade de Letras do Porto-História, II Série, vol. IV, pp. 11-93; Anastásia Mestrinho Salgado e Abílio José Salgado, Formas de Sensibilidade na Assistência Durante a Época dos Descobrimentos, Lisboa, ed. Rei dos Livros, 1992; Paulo Drumond Braga, "A Crise dos estabelecimentos de assistência aos pobres nos finais da Idade Média", in Revista Portuguesa de História, tomo XXVI, Coimbra, 1991, pp. 175-190.

${ }^{\left({ }^{10}\right)}$ A constituição do património da confraria e hospital processa-se, ao que se apura da documentação, da seguinte forma:

\begin{tabular}{|c|c|c|}
\hline Anos & Doações & Compras \\
\hline 1449 & 1 & \\
\hline 1466 & 1 & \\
\hline 1485 & 1 & 1 \\
\hline 1493 & & 1 \\
\hline 1497 & 1 & \\
\hline 1504 & & 1 \\
\hline 1507 & 5 & \\
\hline lotai & 5 & 3 \\
\hline
\end{tabular}

Fonte: A. Misericórdia Batalha, Livro 1, fls. 113v-l 18 - (Cf. Gráfico 1). 
Descortinámos a proveniencia de $22,85 \%$ dos bens e, nestes, o predomínio vai para as doações $(62,5 \%)$ contra $37,5 \%$ de compras $\left({ }^{11}\right)$. É bastante provável, cremos, que a restante percentagem de bens cuja origem nos escapa $(77,14 \%)$ se distribua duma maneira algo próxima, em proporção, da que se apurou nos restantes $22,8 \%$ dos proventos.

A composição da propriedade da instituição é por excelência rural e com particularidades como, por exemplo, a inexistência de vinhas, de ferragiais e de herdades, o que contrasta com outras casas semelhantes conquanto em diferentes centros $\left({ }^{12}\right)$. Embora se situasse dentro da Batalha, centro "para-urbano", só a casa do hospital com o seu quintal e cerrada com árvores, cremos que de fruto, se poderá definir como propriedade "urbana". Isso representa 8,5\% do seu cabedal. Os restantes $91,14 \%$ são plenamente campestres $\left({ }^{13}\right)$.

Duas ilações há a sublinhar deste quadro. A predominância dos campos de pão, as courelas ou terras, e a importância que os

\begin{tabular}{|c|c|c|}
\hline \multicolumn{3}{|c|}{ QUADRO I } \\
\hline \multicolumn{3}{|c|}{ Composição da Propriedade da Confraria de N. Senhora da Vitória } \\
\hline Género & Número & $\%$ \\
\hline Casal & 1 & $2,85 \%$ \\
\hline Casas & 1 & $2,85 \%$ \\
\hline Chouso/Quintal & 1 & $2,85 \%$ \\
\hline Courelas/Terras & 26 & $\mathbf{7 4 , 2 8 \%}$ \\
\hline Matos/Arneiros & 4 & $11,42 \%$ \\
\hline Pomares & 2 & $5,71 \%$ \\
\hline Total & 35 & $100 \%$ \\
\hline
\end{tabular}

(11) Proporções semelhantes para Évora. Vd. Bernardo Vasconcelos e Sousa, ob. cit., p. 41-45.

${ }^{12}$ C. nota 30. Tb. Bernardo Vasconcelos e Sousa, ob. cit., pp. 47-51.

$\left({ }^{13}\right)$ Dada a relatividade desta classificação como bens "urbanos", consideramo-los na globalidade para as restantes ilações. 
matos e arneiros acabam por ter neste conjunto. Além delas é de sublinhar a existência de um casal, com um foro elevado, como se verá, o que aproxima este instituto de entidades eclesiásticas estremenhas $\left({ }^{14}\right)$.

A caracterização da propriedade implica que analisemos ainda as confrontações das terras, o que se pode observar no seguinte quadro:

\begin{tabular}{|l|c|c|c|c|c|}
\hline \multicolumn{7}{|c|}{ QU A D RO II } \\
\hline $\begin{array}{c}\text { Género } \\
\text { Confrontações }\end{array}$ & Casal & $\begin{array}{c}\text { Courelas/ } \\
\text { Terras }\end{array}$ & $\begin{array}{c}\text { Matos/ } \\
\text { Arneiros }\end{array}$ & Pomares & Totais \\
\hline Casais & $\left(1 .^{\mathrm{n}}\right)$ & 1 & & & 1 \\
Vinhas & - & 1 & & & 1 \\
Matos & - & $\left(6 .{ }^{\mathrm{p}}\right)$ & 1 & & 7 \\
Courelas/Terras & - & 69 & 8 & 2 & 79 \\
Caminhos & - & 15 & 2 & & 17 \\
Cursos de Água & - & 2 & - & - & 2 \\
\hline Totais & $(\mathrm{D}$ & 94 & 11 & 2 & 107 \\
\hline
\end{tabular}

a) Trata-se do casal do Hospital, cujas confrontações nos são desconhecidas.

b) Em dois casos são terras que partem com "serra".

É significativo que $87,78 \%$ das propriedades confrontadas são courelas ou terras de cereal e que apenas $10,28 \%$ seja o índice para o espaço florestal. O pomar, com 1,86\%, não passa de uma cultura mínima.

${ }^{(4)}$ Precisamente pela presença do casal e doutras pequenas parcelas de terra. Cf. Ana Maria Rodrigues. "O Domínio Rural e Urbano da Colegiada de São Pedro de Torres Vedras no Final do Século XV" in Revista de História Económica e Social, $\mathbf{n}^{\circ}$ 17, Lisboa, 1986, pp. 78-83. 
No global, as courelas confrontam em $73,4 \%$ com outras terras de pão. Em 15,95\% com caminhos e apenas $2,1 \%$ com cursos de água. Por sua vez, os matos e arneiros confrontam em 7,47\% com terras de pão e apenas em 1,88\% com caminhos. Quanto aos pomares, confrontam apenas com terras de trigo (Gráficos 2 e 3 ).

Podemos retirar algumas ilações que julgamos essenciais.

O elevado número de terras que confronta noutras do mesmo género atesta a contiguidade de culturas e, no caso, a hegemonia do trigo $\left({ }^{15}\right)$. As referências a caminhos, embora menores, são de considerar, tanto mais que estes eram essenciais ao escoamento dos produtos para os centros armazenadores, quer urbanos, quer de outro tipo. A presença da mata atesta não tanto o espaço inculto mas antes a sua importância para a economia doméstica das populações e também no quotidiano do Hospital $\left({ }^{16}\right)$.

A fraca representatividade da vinha é mais difícil de explicar, embora mereça reparo. Efectivamente, isso parece corresponder à pouca surgência de cursos de água, sabido como é que o vinhedo, tendencialmente, era cultivado nas suas proximidades $\left({ }^{17}\right)$. O segundo reparo, que justifica uma certa estranheza, é a proximidade da Batalha, em cujo Mosteiro trabalhavam largas centenas de operários, sem contar com outros serviçais e habitantes da zona, que deveriam consumir, sem timidez, bastante vinho. O facto de a confraria não possuir uma única vinha $\mathrm{e}$, mesmo, da sua fraca aparição no conspecto paisagístico esboçado (só uma courela de terra confronta em vinha, caso único (cf. Quadro II e Gráfico 3)),

$\left({ }^{15}\right)$ Cf. Maria Helena Coelho, op. cit., p. 152; Saul António Gomes, op. cit., pp. 195$-196$.

${ }^{16}$ ) Saul Gomes, op. cit., p. 197. Entre as diversas obrigações que o hospital da confraria tinha, estava, precisamente, a de durante o Inverno adquirir três carradas de lenha para aquecer os doentes e pobres (Tombo, fls. 14-v, 32-v, 38-v, et alii).

${ }^{(1)}$ R. Durand, "La vigne et le vin dans le bassin du Mondego au Moyen Age (XII-XIII' siècles)", in Arquivos do Centro Cultural Português, V, Paris, 1972, pp. 32-33; Maria Helena Coelho, op. cit., p. 152; Bernardo V. e Sousa, op. cit., pp. 77-81; Iria Gonçalves, O Património do Mosteiro de Alcobaça nos Séculos XIV e XV, Lisboa, Univ. Nova, 1989, pp. 81-87. 
não se compreenderá a não ser pela razão da contiguidade de culturas, é certo, e também por ser um género porventura menos disponível, na época, para aquisição, mormente por instituições com fundos financeiros de maneio particularmente exíguos, como seria o caso dos desta confraria de mesteirais.

As referências a matos e arneiros, sobretudo estes, indicam que a confraria tem, no seu património, terras de fraca produtividade, de segunda categoria. Poderá isto significar, ainda, que a disponibilidade de terras, tanto as doadas como as adquiridas por compra, não ultrapassava o que poderemos designar por terras marginais? Aparentemente sim, mas só o cálculo da produtividade média por hectare, no entanto, poderia esclarecer satisfatoriamente esta questão $\left({ }^{18}\right)$.

Isto significará a realidade dum espaço plenamente rural, predominantemente marcado pelas culturas extensivas, já fora da área periurbana imediata de Leiria, - centro urbano colossal face aos pequenos povoados do termo - debruçado sobre o cultivo do trigo, preferencialmente $\left({ }^{19}\right)$.

A propriedade é esmagadoramente muito pequena.

$81,24 \%$ fica aquém do meio hectare, $12,5 \%$ entre meio e um hectare, 6,24\% entre um e cinco hectares. São números bastante inferiores aos apresentados para Santarém $\left({ }^{20}\right)$ ou Évora $\left({ }^{21}\right)$. (Cf. Gráfico 4).

A relação comprimento/largura é, no entanto, próxima da que se encontrou para as confrarias de Santarém $\left({ }^{22}\right)$ predominando a

$\left.{ }^{18}\right)$ Alguns dos foreiros trazem duas e mais terras da confraria, confrontando estas com as suas próprias explorações. É o caso de João Eanes com sete terras aforadas da confraria, três delas, de seguro, confinantes com explorações suas (Tombo, fls. 114$-116 v)$.

$\left.{ }^{(19}\right)$ Cf. Iria Gonçalves, op. cit., pp. 65-80; Saul Gomes, op. cit., 201-204.

$\left({ }^{20}\right)$ Cf. Manuela Silva e Sílvio Conde, op. cit., p. 80.

$\left(^{21}\right)$ Cf. Bernardo V. e Sousa, op. cit., pp. 77-85,99.

$\left({ }^{2}\right)$ Vide ob. citada na nota 20 , p. 83. Aplicam-se, também aqui, as palavras de Iria Gonçalves, quando escreve: "Essas courelas podiam apresentar formas e tamanhos muito variados, mas, maioritariamente, eram pequenas e rectangulares, quantas vezes bem 
relação de $1 / 2$ a 4 e de 1/1. (Cf. Gráfico 5). A paisagem agrária formatava-se, pois, na confluência das disponibilidades técnicas locais, - em que o uso do jugo de bois com charrua e arado proliferava, pelo menos nas terras mais ribeirinhas aos rios Lis e Lena, bem como aos seus afluentes - na imposição da orografía regional e, ainda, no cadastro duma propriedade extremamente disputada, se de boa produtividade, tanto quanto repartida pelas partilhas geracionais em que era envolvida. Razão esta, aliás, de importância maior, pois que lidamos com uma instituição cujo património resulta fundamentalmente do conspecto da divisão da propriedade rural pertencente a comunidades mesteirais, por excelência alodial.

\begin{tabular}{|c|c|c|c|c|}
\hline \multicolumn{5}{|c|}{ QUADRO III } \\
\hline \multicolumn{5}{|c|}{ Propriedade Rústica - Dimensões e Áreas das Terras } \\
\hline \multicolumn{2}{|c|}{ Dimensões } & \multirow{2}{*}{$\begin{array}{c}\text { Ratio } \\
\text { c-l }\end{array}$} & \multirow{2}{*}{$\begin{array}{c}\text { Área } \\
\text { em m } \mathbf{m}^{2}\end{array}$} & \multirow{2}{*}{ Observações } \\
\hline Varas & Metros & & & \\
\hline $\begin{array}{rrr}c & -140 \\
1 & - & 3\end{array}$ & $\begin{array}{r}154 \\
3,3\end{array}$ & 46,66 & 508,2 & \\
\hline $\begin{array}{ccc}\mathbf{c} & - & 90 \\
1 & - & 12 \\
1^{\prime} & - & 17\end{array}$ & $\begin{array}{l}99 \\
13,2 \\
18,7\end{array}$ & 7,5 & 918,5 & Diagonal-87.6 m \\
\hline $\begin{array}{lll}c & -290 \\
1 & -260 \\
\end{array}$ & $\begin{array}{l}319 \\
286\end{array}$ & 1,11 & 9123,4 & \\
\hline $\begin{array}{lll}c & - & 40 \\
1 & - & 30\end{array}$ & $\begin{array}{l}44 \\
33\end{array}$ & 1,33 & 1452 & \\
\hline $\begin{array}{ccc}c & - & 26 \\
1 & - & 5 \\
\end{array}$ & $\begin{array}{r}28,5 \\
5,5\end{array}$ & 5,18 & 156,7 & \\
\hline $\begin{array}{lll}c & - & 25 \\
1 & - & 23\end{array}$ & $\begin{array}{l}27,5 \\
25,3\end{array}$ & 1,08 & 695,7 & \\
\hline
\end{tabular}

estreitas, embora compridas, estreitamento que eventuais partilhas acentuariam ainda." ("Entre o Campo e a Cidade na 2. ${ }^{a}$ Metade do Século XIV", in Estudos Medievais, n. ${ }^{\circ}$, Porto, pp. 79-80). 


\section{QUADRO III (Cont.)}

Propriedade Rústica - Dimensões e Áreas das Terras

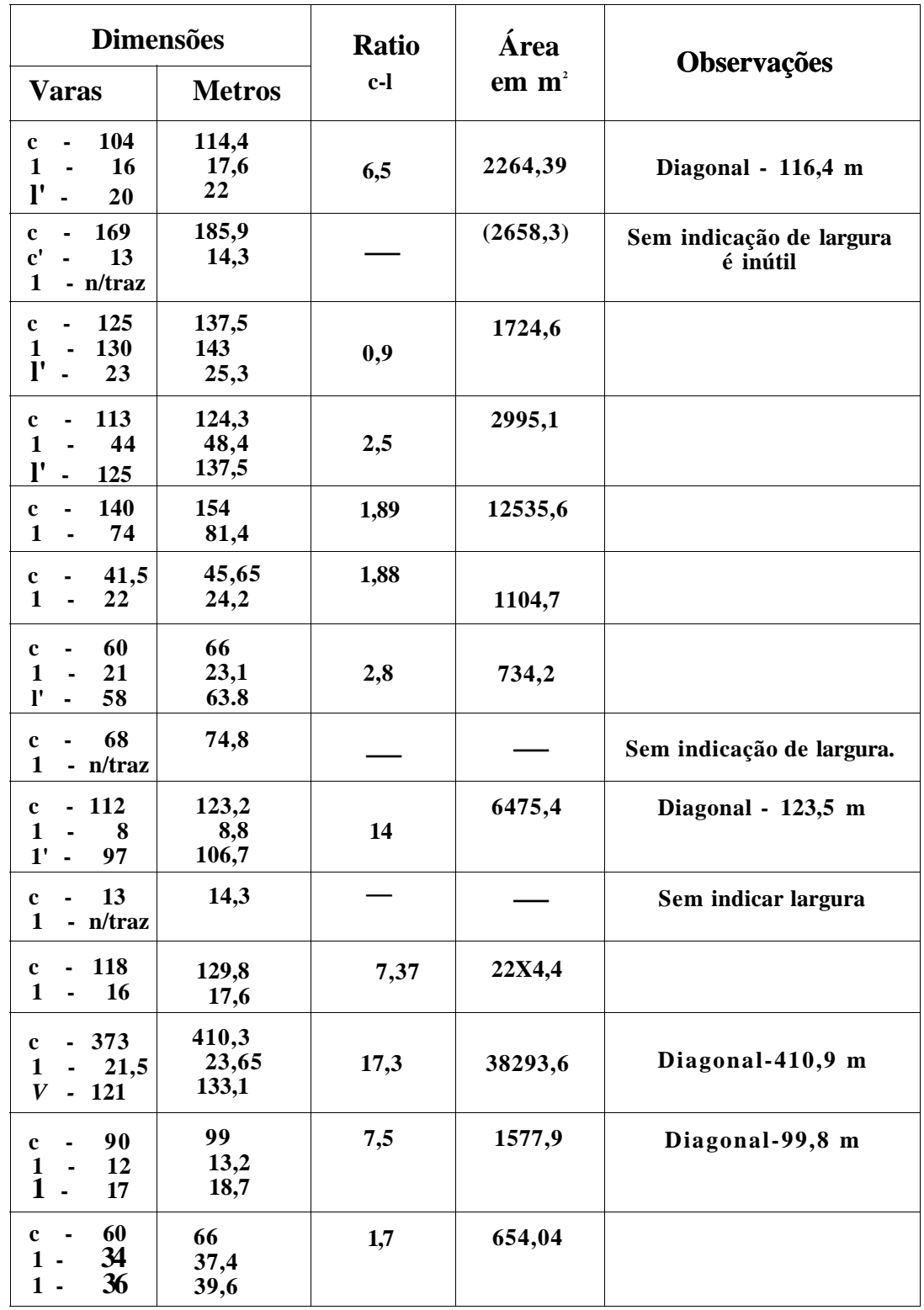


QUADRO III (Cont.)

Dimensões e Áreas das Terras

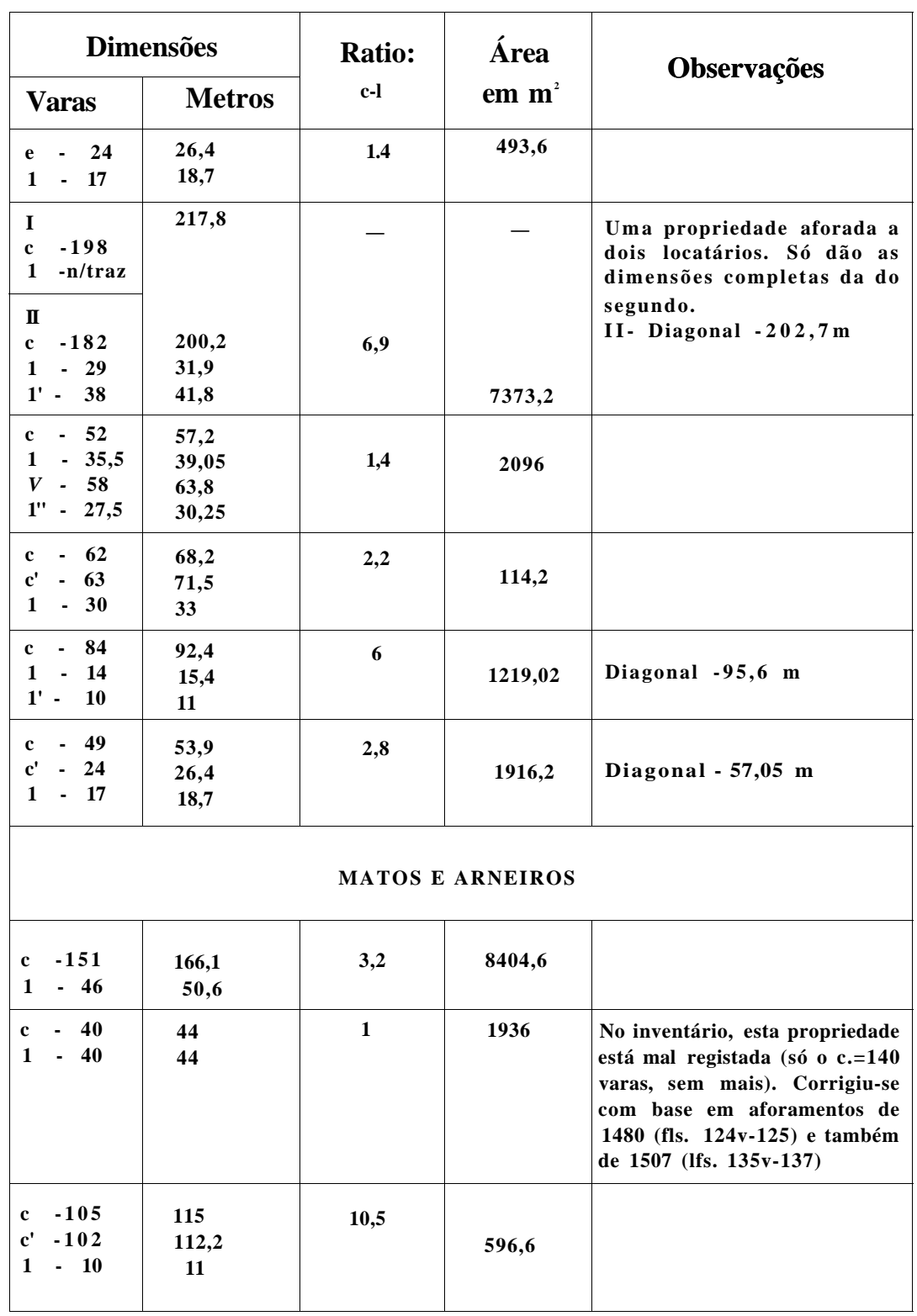




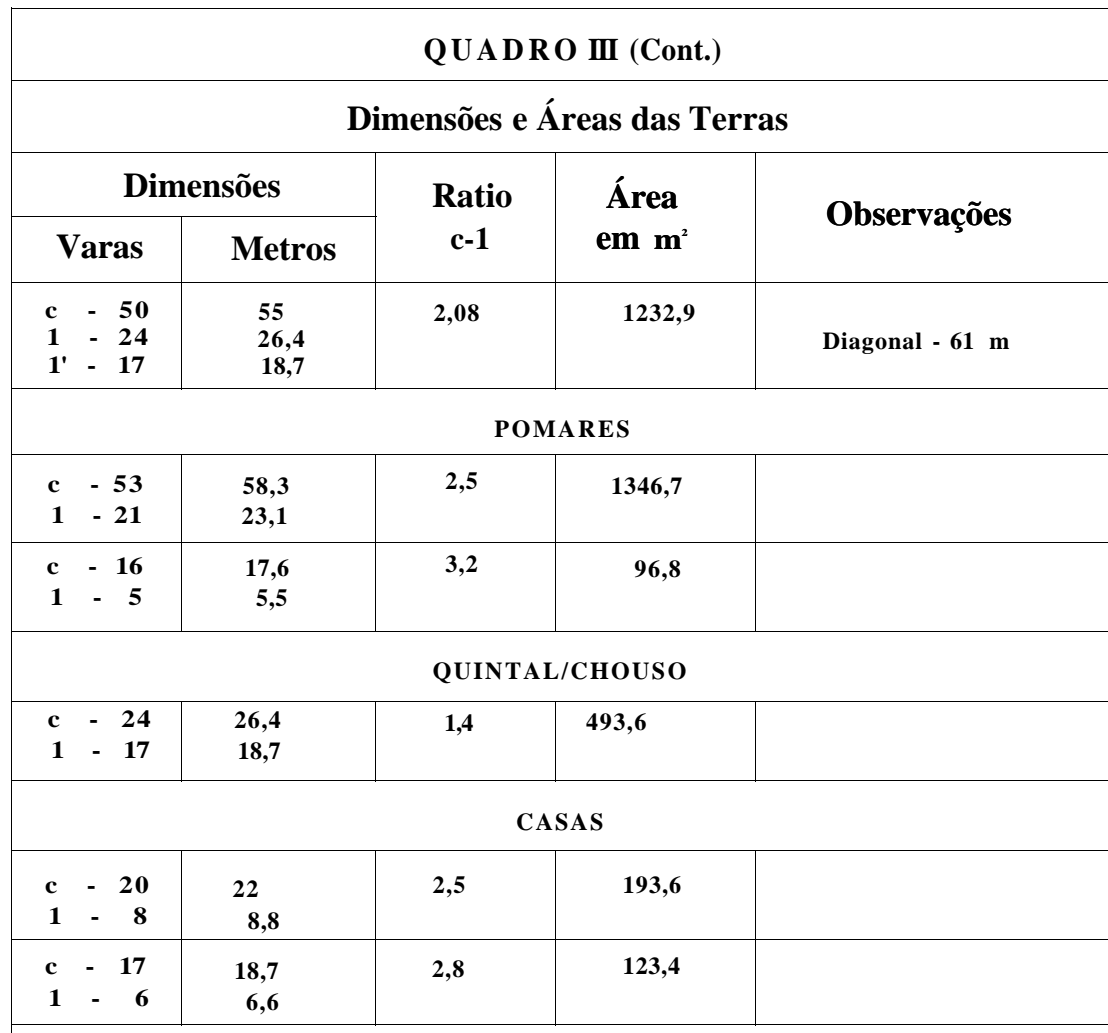

Notas:

*) - As dimensões são apresentadas em índices médios, conquanto rigorosos. Os dados fornecidos pelo inventário podem nem sempre estar correctos por lapso de cópia. Detecta-se um exemplo que comprova a asserção. De qualquer forma será uma excepção.

- Em 35 propriedades, apenas ignoramos as áreas de três delas. Um caso, ainda, de que só conhecemos uma parte, porquanto a propriedade estivesse aforada a dois usufrutuários, só se apresentando elementos para um caso.

Siglas:

c-comprimento;

c' - comprimentos;

1 - largura;

$V$ - larguras;

m - metros.

Um quadro estruturalmente idêntico pode ser visto em: Bernardo Vasconcelos e Sousa, $A$ Propriedade das Albergarias de Évora nos Finais da Idade Média, cit., pp. 79-85.

Vara = 1,10 m segundo A. H. de Oliveira Marques," Pesos e Medidas", in Dicionário de História de Portugal (dir. Joel Serrão), Vol. V, Iniciativas Editorias, Lisboa (s.d.), pp. 67-72. Fonte:

A. Misericórdia da Batalha, Livro 1, fls. 113v-l 18. 
A atendermos aos dados de inícios do século XVI, sejam os consignados no tombo do Hospital, sejam os de alguns em prazamentos $\left({ }^{23}\right)$, verificamos que há um predomínio dos pequenos foros. Dos que conseguimos apurar, metade situa-se entre um a dois alqueires de trigo e $90 \%$ não ultrapassam os quatro alqueires $\left({ }^{24}\right)$. Com base nos mesmos elementos podemos inferir que do rendimento das terras da confraria, $87 \%$ são relativos a trigo e $12,6 \%$ a dinheiro $\left({ }^{25}\right)$. Esta circunstância explica-se pelas próprias dimensões das explorações.

$\left.{ }^{(23}\right)$ Os emprazamentos conhecidos datam de: 1) 1505, Março, 26, (Tombo, fls. 131-132); 2) 1505, Março, 26, (id., fls. 132-133v); 3) 1505, Março, 26, (id., fls., 133v-134v); 4) 1507, Dezembro, 28, (id., fls. 135v-137) (data crítica corrigida).

Só encontrámos um prazo para o século anterior, precisamente de 1480, Setembro, 8 (Tombo, fls. 124v-125), que estipula um cânon de 60 reais de foro; este mesmo, em 1507 (prazo acima citado, deste ano), em novo contrato, passa a ter o cânon pago em géneros ( 2 alqueires de trigo).

${ }^{(4)} O$ quadro dos foros resume-se ao seguinte:

\begin{tabular}{|c|c|c|}
\hline Alqueires de trigo & N. $^{\circ}$ & $\%$ \\
\hline $1-2$ & 5 & $50 \%$ \\
$3-4$ & 4 & $40 \%$ \\
$5-10$ & 1 & $10 \%$ \\
\hline Total & 10 & $100 \%$ \\
\hline
\end{tabular}

Três das trinta e cinco propriedades do Hospital são isentas de foro porque entregues ao hospitaleiro como paga dos seus serviços. Em 1507, uma terra não está aforada a ninguém, ignorando-se porquê. Outra, nessa data, é dada "à ração" (Tombo, fls. 113v-l 18).

Os números apresentados, no Quadro acima, indicam a) que 31,2\% dos foreiros pagam um pouco menos de 30 alqueires de trigo; b) conjugados com o seguinte esquema podemos ainda acrescentar que, em média, de 1517, 1518 e 1519, os foros em trigo rondaram as quantias de 65 e 3/4,73 e 71 alqueires respectivamente, ou seja, uma média próxima dos 70 alqueires por ano. Dos foros em dinheiro, mas para 1518 e 1520, sabemos ascenderem a 360,410 e 430 reais respectivamente. Conjugando, em dinheiro (1 alqueire = 40 reais, em média por defeito) estes elementos, a título meramente aproximativo ou relativo, teremos $87,38 \%$ dos foros relativos a trigo e $12,6 \%$ a dinheiro (cf. nota seguinte). Estes índices não andarão muito longe dos de finais do século anterior.

$O$ casal da instituição com os seus 30 alqueires de trigo, número para 1483 a 1485 (Tombo, fls. 125v-126v), é um dado à parte.

$\left({ }^{25}\right)$ Comparando, após redução a dinheiro, os foros em géneros e em dinheiro, seguindo argumentos apresentados na nota anterior, teremos a título de exemplo, para 1519: 71 alqueires $x 40$ rs. $=2480$ rs. $(87,3 \%)$

$$
\text { renda }=410 \text { rs. }(12,6 \%) \text {. }
$$

Os preços, como se observará, são instáveis nos anos 1517-1520, a saber: 1517-66 
Mas se o predomínio dos foros é de reduzida monta, há que notar o extremo oposto. É o caso do casal da instituição cujo cânon ascendia aos trinta alqueires de trigo na década de $1480\left({ }^{26}\right)$, caso verdadeiramente excepcional.

Foros, na maior parte, de terras de pão e com a natural preferência pelo pagamento mais estável e seguro em géneros $\left({ }^{27}\right)$, eis o que individualiza esta instituição situada em pleno espaço rural (apesar de núcleos populacionais circundantes com real peso, caso da Batalha e do Reguengo $\left({ }^{28}\right)$ ), de outras sediadas em centros urbanos de magna importância como Santarém $\left({ }^{29}\right)$ ou Évora $\left({ }^{30}\right)$, que vêem os seus foros pautarem-se por uma outra diversidade $\left({ }^{31}\right)$.

$\mathrm{O}$ cadastro da propriedade deste instituto revela-se numa área cujo raio atinge no seu ponto máximo cerca de oito quilómetros (terras do Reguengo). De certa forma é um património aparentemente concentrado, na medida em que se reduz à proximidade da instituição.

As suas parcelas, contudo, caracterizam-se pela não contiguidade, antes pelo contrário, definindo-se pela dispersão, pelo minifundismo, o que se compreende tendo em atenção o estado avançado

reais/alq.; 1518-45 reais/alqueire; $1519-40$ reais/alqueire; $1520-55$ reais/alqueire; (Tombo, fls. 8-v, 14-v, 32-v, 38-v, respectivamente). Não surgem quaisquer referências a miunças ou a direituras.

$\left.{ }^{26}\right)$ O casal era, como se escreveu, uma excepção com os seus trinta alqueires de pão por ano, em foro (Tombo, fls. 125v-126v). Em 1485, o locatário, beneficiado em Sta. Maria da Pena de Leiria, entregaria duas terras à confraria em pagamento dadívida do ano 1483 (Tombo, id.).

$\left({ }^{27}\right)$ Cf. nota 23. Vd. Iria Vicente Gonçalves, O Património do Mosteiro de Alcobaça..., pp. 189-203; M. Helena Coelho, O Baixo Mondego..., I, pp. 309-320.

${ }^{(28)}$ Saúl Gomes, $O$ Mosteiro de Santa Maria da Vitória..., pp. 23-29.

$\left({ }^{29}\right)$ Vd. M. Manuela Silva e Manuel Sílvio Conde, "Recursos Económicos de algumas instituições de assistência de Santarém nos finais da Idade Média", in Actas das Jornadas (...). Portugal e a Crise Geral dos Séculos XIV/XV. 1383/1385, Lisboa, 1985, pp. 69-99.

${ }^{\left({ }^{3}\right)}$ Vd. Bernardo Vasconcelos e Sousa, A Propriedade das Albergarias de Évora nos finais da Idade Média, cit., pp. 103-109.

${ }^{(1)}$ Como se referiu, não há elementos, para Leiria, que permitam uma análise mais pormenorizada quanto à envolvência económico-agrária deste instituto assistencial. 
da colonização agrária que atingira esta área, desde muito cedo, aliás, só se tornando disponíveis as terras potencialmente menos produtivas.

A concentração do seu património dentro do referido raio de cerca de oito quilómetros explica-se não por razões de comodidade administrativa, mas por causas de disponibilidade de solos. Por outro lado, estamos perante estruturas económicas de um reduzido domínio que se insere no conjunto da pequena produção campesina em correspondência com as condições demográficas e edológicas da região. O minifundismo que testemunha, a própria não contiguidade no terreno das parcelas, a sua reduzida superfície são factores que devem corresponder a uma origem alodial. De facto, teriam sido proprietários alodiais, do tipo detectado para os termos de Montemor-o-Velho e de Coimbra, os principais senão únicos dotadores deste hospital do termo leiriense $\left({ }^{32}\right)$.

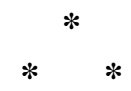

A escassez de informação sobre este mesmo tema relativa a outras pequenas instituições laico-religiosas da região não nos permite avançar muito mais para além do que se registou nas páginas anteriores. A maior parte dessas entidades tinham necessariamente património rural ou urbano a que se somaria todo um conjunto de pequenas doações ocasionais, normalmente dinheiro. E o caso da Confraria de Várzeas, que recebe meio maravedi em testamento de $1278\left({ }^{33}\right)$, e da do Espírito Santo, de Leiria, à qual é

$\left.{ }^{(32}\right)$ Confronte-se, embora numa outra escala, a propósito, o trabalho de Luis Martínez García, El Hospital del Rey de Burgos. Un Señorio Medieval en la Expansion y en la Crisis (Siglos XIII y XIV), ed. Garrido Garrido, Burgos, 1986, p. 235. Para as dimensões da propriedade alodial que citámos veja-se Maria Helena Coelho, op. cit., I, pp. 84-88; Iria Gonçalves e Fátima Botão, "As Confrarias Medievais de Alcanena", pp. 42-46.

$\left(^{33}\right)$ ANTT - Alcobaça, 1." incorporação, m. ${ }^{\circ} 16$, n. ${ }^{\circ}$ 19. Testamento de Estêvão Gomes de 1278, Julho, 18, em Monte Redondo. 
legado um maravedi pouco antes de $1309\left({ }^{34}\right)$.

Estamos mais informados para o século XV. A Confraria de Alcamim (Vermoil), tinha duas herdades junto da Ribeira de Cabruncas, que partiam com propriedades do Mosteiro de Alcobaça $\left(^{35}\right)$, uma herdade ao Porto das Pedras (Litém) $\left(^{(36}\right)$ e outra na aldeia do Vermoil $\left({ }^{37}\right)$, isto em 1435 . Também a Confraria do Espírito Santo do Poial possuía, nesse ano, uma herdade em Cabruncas que partia com o citado instituto cisterciense ${ }^{{ }^{38}}$ ). Os "marinheiros de Paredes" tinham um "campo" à Cabeça de João Neto, junto de Brancas $\left({ }^{39}\right)$. Nas proximidades do fértil Monte do Trigo (Brancas) haviam os "universairos de Leiria" uma herdade $\mathbf{0}^{\circ}$ ). Os confrades da Capela de Sta. Maria, sita na igreja paroquial de Sto. Estêvão de Leiria, alegam, em 1471, que os bens de raiz dessa instituição valeriam quinze mil reais $\left({ }^{4}\right)$ - A Confraria do Reguengo de Magueixa possuía diversas terras nas imediações da aldeia $\left({ }^{42}\right)$.

Tanto a Confraria de Alcamim (Vermoil), como a do Espírito Santo do Poial possuíam terras nas imediações das aldeias onde se

$\left({ }^{34}\right)$ Ibidem, $2 .^{a}$ incorpor., m. ${ }^{\circ} 10$, n. $^{\circ} 230$ (8). Documento de 1309, Abril, 16, Leiria em que há notícia de Domingos Peres, alcobacil em Leiria, ter deixado essa quantia à mesma Confraria.

$\left({ }^{35}\right)$ Ibidem, Livro 15, fls. 275-v. De 1435

$\left({ }^{36}\right)$ Ibidem, Livro 15, fl. 277v. De 1435.

${ }^{(37)}$ Ibidem, Livro 15, fls. 275v e 279v. De 1435.

$\left({ }^{s}\right)$ Ibidem, Livro 15, fl. 275. De 1435.

$\left(^{30}\right)$ Ibidem, Livro 15, fl. 259. De 1435. "Marinheiros de Paredes", entendemos esta expressão como correspondendo a uma associação do tipo de qualquer confraria profissional.

(“) Ibidem, Livro 15, fls. 260-v. ${ }^{\circ}$. De 1435.

( ${ }^{41}$ ANTT-Chancelaria de D. Afonso V, Livro 16, fls. 82v-83. Documento de 1471, Abril, 26, Santarém. Trata-se de uma carta de licença para administração desses bens.

${ }^{(42}$ ANTT-Alcobaça, Livro 135, doc. 66, fls. 83-84v. De 1510. Terras em Figueira dos Santinhos e em Longas.

Confronte-se, na generalidade, Manuela Santos Silva," A Assistência Social na Idade Média. Estudo comparativo de algumas instituições de beneficência de Santarém", in Estudos Medievais, n. ${ }^{\circ}$, Porto, 1987, pp. 171-242, especialmente pp. 203-226. Neste estudo analisam-se instituições sediadas no centro urbano, o que contrasta, no nosso caso, com o número dos exemplos citados que, como se indica, se situam no espaço rural. Esta diferença pode, talvez, tornar injustificado um quadro de análise ou de comparação entre Santarém e Leiria.... 
situavam. Esta proximidade verifica-se ainda no caso de certas albergarias. A Albergaria da Maceira teria duas courelas, pelo menos, junto da sua casa, por $1324\left({ }^{43}\right)$. A Albergaria de Cortes, por 1347-1361, havia herdades na aldeia que partiam com os monges de Alcobaça $\left({ }^{44}\right)$. A do Furadouro (junto de Pinhal Verde/Barreira) tinha uma vinha nas imediações de Leiria $\left(^{45}\right)$. A de Agodim, em 1435 , possuía herdade junto dessa aldeia $\left(^{46}\right)$. A do Reguengo terá uma terra em Vale das Freiras (Alqueidão da Serra) antes de $1535\left({ }^{47}\right)$.

Todas estas situações indicam distâncias não superiores aos cinco quilómetros e, estes, só em casos excepcionais.

No panorama destas instituições assistenciais a gafaria de Sto. André, edificada junto do centro urbano, é um caso particular. Fundada ainda durante a primeira fase da colonização desta região, vemos as suas propriedades confinarem com a de poderosos institutos religiosos como a Ordem do Templo (em Freixo, cerca de 1230) $\left({ }^{48}\right)$ ou Alcobaça (no Cuncadoiro, em $1410\left({ }^{49}\right)$ e seguintes $\left({ }^{50}\right)$, nas Brancas, por $1435\left({ }^{51}\right)$ e na Guimarota, também nesse ano $\left(^{52}\right)$. Destacam-se ainda as suas vinhas junto de Leiria, no

( $\left.{ }^{43}\right)$ ANTT - Sé de Coimbra, 2. ${ }^{a}$ incorpor., m. ${ }^{\circ}$ 29, n. ${ }^{\circ}$ 1223. De 1324, Julho, 5, Maceira. Ibidem, $2 .^{a}$ incorpor., $\mathbf{m} .^{\circ}$ 28, n..$^{\circ}$ 1168. De 1394, Outubro, 22, Maceira. Ibidem, Livro 1 A, fls. 224-225. De 1451, Julho, Leiria.

$\left(^{4}\right)$ Idem, Alcobaça, 2." incorpor., m. ${ }^{\circ}$ 51, n. 1400 (1). De 1347-1361. Leiria.

(') Idem, Sta. Clara de Coimbra, cx. 1. séc. XIV, "n. ${ }^{\circ}$ 67". De 1361, Agosto, 17,

(') Idem, Alcobaça, Livro 15, fl. 269v. De 1435.

(") Idem, Mosteiro de Cós, m. ${ }^{\circ}$ 1, doc. 28. De 1535, Janeiro, 7, Porto de Mós.

$\left({ }^{48}\right)$ Idem, Mestrados, fls. 50v. Idem, Gavetas, VII, $\mathbf{m} .{ }^{\circ} 4$, n. ${ }^{\circ}$. Documento não datado, mas de cerca de 1250 , pela crítica interna do mesmo. É certamente esta propriedade a que se refere um documento de 1337, Agosto, 17, Leiria, como partindo com herdade de Martim Ovelheiro: Idem, Sta Clara de Coimbra, particulares, m. ${ }^{\circ}$ 3, n. 35 .

$\left(^{49}\right)$ ANTT-Alcobaça, 2. ${ }^{a}$ incorpor., ${ }^{\circ}{ }^{\circ} 12, n .{ }^{\circ} 297$ (29). De 1410. Trata-se de um olival. Ibidem, Livro, 15, fl. 229v. De 1435. Ibidem, Livro 135, doc. 33, fls.42v-43. De 1460, Abril, 29.

$\left({ }^{50}\right)$ Ibidem, Livro 15, fl. 229v. De 1435. Ibidem, Livro 135, doc. 33, fls. 42v-43. De 1460, Abril, 29.

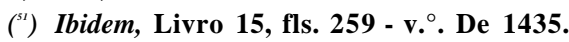

$\left(^{(2)}\right.$ Ibidem, Livro 15, fls. $217-$ v. ${ }^{\circ}$. De 1435. 
Arrabalde de Além $\left({ }^{53}\right)$, na Portela $\left({ }^{54}\right)$ e nas Olhalvas $\left({ }^{55}\right)$. O cadastro das suas terras e bens, feito em 1502, deveria, se não se tivesse perdido, conter informes bastante mais pormenorizados que aqueles que conseguimos reunir $\left({ }^{56}\right)$.

Os elementos aduzidos, contudo, permitem concluir que a pequena propriedade agrícola constituía uma mancha real distribuída por todo o termo de Leiria desde relativamente cedo. Mas, em Quatrocentos, a situação caracterizar-se-á pela sua maior fragmentação, em consequência do próprio crescimento populacional que, entretanto, e ultrapassada a crise de profunda mortalidade de 1348 , levava à necessidade duma redistribuição da terra quer a nível familiar, quer a nível geral da constituição ou consolidação de patrimónios mais amplos próprios de instituições dominiais eclesiásticas ou laicais.

A maior parte dos cadastros temporais das confrarias desta região denunciam o próprio estrato socio-económico dos seus agentes humanos, das suas disponibilidades como pequenos proprietários alodiais quer enquanto doadores dalgumas parcelas de terra a esses institutos de solidariedade mútua, quer enquanto adquirentes ou vendedores.

Ainda que com características muito peculiares, o património da confraria do Hospital de Sta. Maria da Vitória constitui um exemplo significativo da realidade histórica do processo português, na zona estremenha, no que respeita à divisão da propriedade e à dinâmica dos usos sociais que sobre ela incidiam.

\section{SAUL ANTÓNIO GOMES}

$\left(^{(3)}\right.$ Idem, Sé de Coimbra, m. ${ }^{\circ} 15$, n. $^{\circ}$ 34. De 1257, Fevereiro, Leiria. Idem, Alcobaça, 1. ${ }^{a}$ incorp., $\mathrm{m} .{ }^{\circ} 14, \mathrm{n} .{ }^{\circ}$ 4. De 1273 , Junho, 14, Leiria.

$\left(^{(s)}\right.$ Idem, Alcobaça, $1 .^{a}$ incorp., m. ${ }^{\circ} 18$, n. ${ }^{\circ} 44$. De 1289, Abril, 14, Leiria.

(') Idem, Alcobaça, Livro 15, fl. 229v. De 1438.

$\left({ }^{50}\right)$ Registo da feitura e entrega do tombo dos bens da gafaria, em 1502, Novembro, 26, Leiria, em ANTT, Sta. Cruz de Coimbra, 2." incorp., m..$^{\circ} 13$, doc. do alm. 28, m..$^{\circ}$, n. ${ }^{\circ}$ 11. Daqui se colhe a notícia de terem sido feitos dois tombos. Um para o prior de Sta. Cruz e outro para o Concelho a quem pertencia, aliás, a administração da gafaria. Os seus informes permitiriam, quiçá, entrever aproximações com os resultados obtidos por Manuel Sílvio Alves Conde para a gafaria de S. Lázaro de Santarém, ("Subsídios para o Estudo dos Gafos de Santarém. (Séculos XIII-XV)", in Estudos Medievais, n. ${ }^{\circ}$, Porto. 1987, pp. 99-170, especialmente as pp. 142-155). 


\section{APÊNDICE}

Gráfico 1: Compras e doações da Confraria

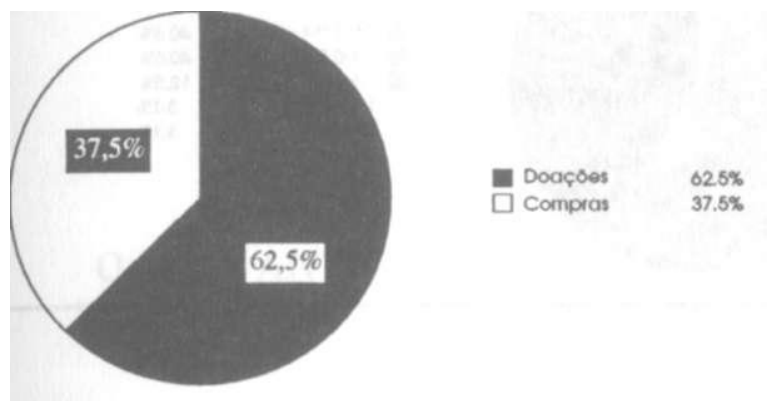

Gráfico 2: Terras confrontadas

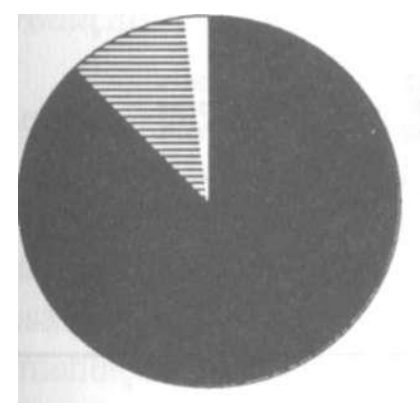

Gráfico 3: Confrontações das courelas

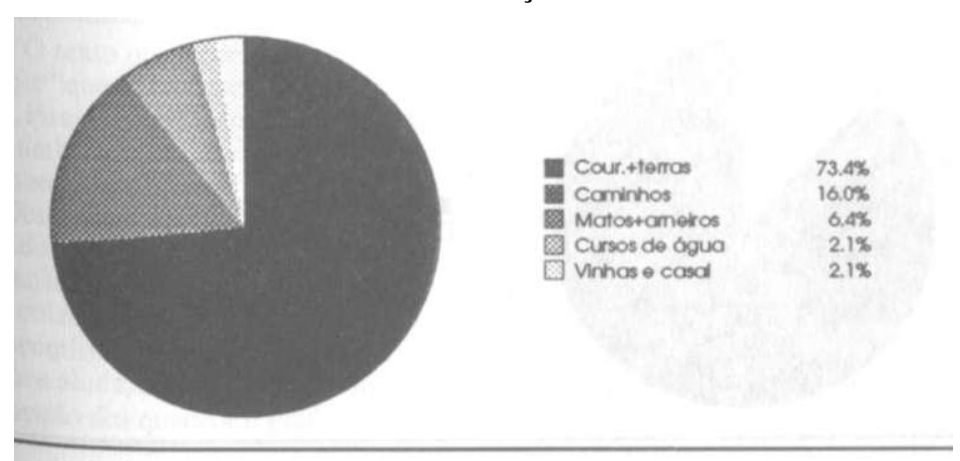




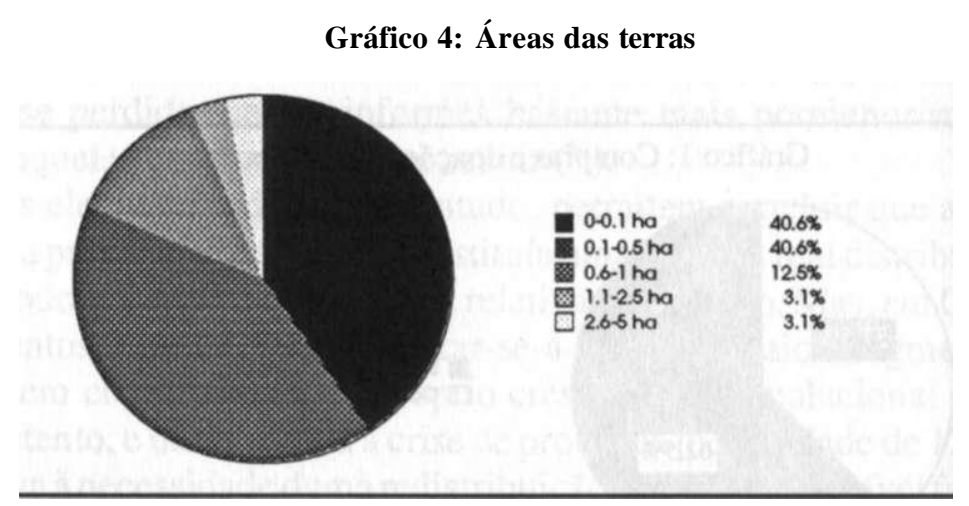

Gráfico 5: Relação comprimento/largura das terras
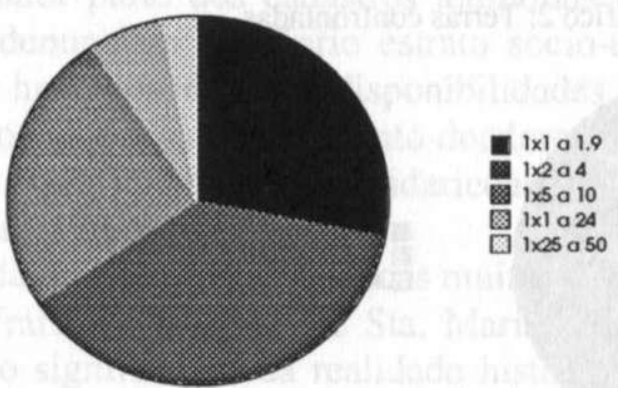

$28.1 \%$

$37.5 \%$

$25.0 \%$

$6.3 \%$

$3.1 \%$

Gráfico 6: Foros em géneros e em renda pecuniária (1519)

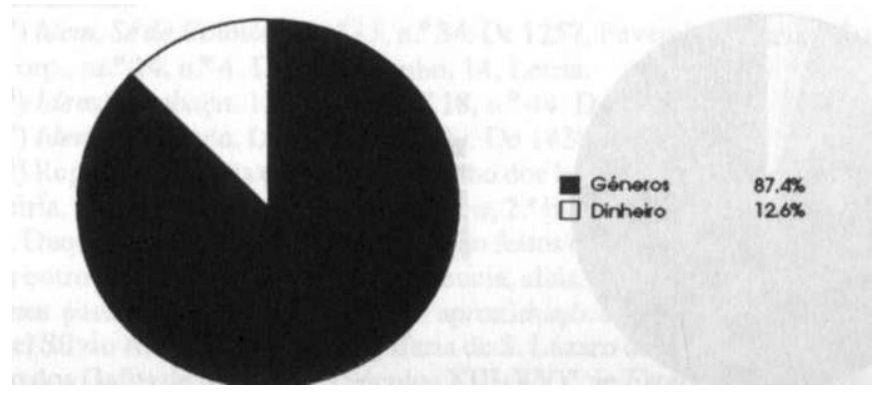

